\title{
DAMPAK HUTAN KEMASYARAKATAN TERHADAP PENGENTASAN KEMISKINAN RUMAHTANGGA SEKITAR HUTAN DI KECAMATAN BATUKLIANG UTARA KABUPATEN LOMBOK TENGAH
}

\section{IMPACT OF COMMUNITY FOREST ON POVERTY ALLEVIATION OF NEAR FOREST HOUSEHOLD IN SUB-DISTRICT OF NORTH BATUKLIANG OF CENTRAL LOMBOK}

\author{
Addinul Yakin, L. Sukardi, M. Yusuf, Syarif Husni \\ Program Studi Agribisnis Fakultas Pertanian UNRAM
}

\begin{abstract}
ABSTRAK
Kawasan pegunungan Rinjani, khususnya resort Setiling Batukliang Utara Kabupaten Lombok Tengah memiliki fungsi biologi, ekologis, dan estetika serta sosial-ekonomi bagi masyarakat sekitar hutan. Deforestrasi sering dikaitkan dengan tingkat kemiskinan masyarakat sekitar hutan, sehingga dengan diberikannya Hutan Kemasyarakatan $(\mathrm{HKm})$ di wilayah tersebut dapat meningkatkan pendapatan masyarakat dan menekan kemiskinan. Penelitian ini telah dilaksanakan dengan menggunakan metode deskriptif-eksploratif-partisipatif dengan mengkombinasikan studi dokumen, wawancara terstruktur, indepth interview, serta diskusi kelompok terarah (FGD) terbatas. Penelitian dilakukan desa Aik Berik dan Desa Setiling dengan jumlah responden sebanyak 40 orang, dengan juga melibatkan tokoh masyarakat di wilayah tersebut. Data yang telah dikumpulkan dianalisa secara deskriptif analisis pendapatan rumahtangga dan pendapatan per kapita yang kemudian digunakan untuk menganalisis tingkat kesejahteraan masyarakat berdasarkan tiga standar yang berbeda, yaitu Sajogyo, BPS, dan Bank Dunia. Hasil studi menunjukkan bahwa: 1) rata-rata total pendapatan rumahtangga masyarakat sekitar hutan mencapai Rp. 20.057 .950 yang terdiri dari Rp. 13.597 .950 (67,79\%) dari sektor pertanian dan Rp. 6.460 .000 (32,21\%) dari sektor non pertanian dengan pendapatan per kapita sebesar Rp. 4.667.549,- per tahun; 2) berdasarkan kriteria BPS, masyarakat sekitar hutan di kecamatan Batukliang Utara masuk kategori tidak miskin, selanjutnya berdasarkan kriteria Sayogyo menghasilkan kategori hampir miskin, dan Kriteria bank Dunia manghasilkan kategori miskin, sehingga ketiganya memberikan tingkat kesejahteraan yang relatif berbeda; 3) Adanya Hkm telah mampu meningkatkan kesejahteraan masyarakat sekitar hutan karena mampu meningkatkan pendapatan per kapita masyarakat sebesar 22,18 persen dan telah mampu mengentaskan kemiskinan 7,5 sampai 22,5 persen. Oleh karena itu disarankan agar perbaikan ekonomi masyarakat sekitar hutan harus dipercepat melalui pola pembinaan dan pengembangan pada bidang-bidang usaha yang menjadi kekuatan utama mereka yaitu kehutanan, peternakan, dan perkebunan serta juga mendorong peningkatan kegiatan perdagangan dan ekonomi produktif skala rumahtangga.
\end{abstract}

Kata kunci: kemiskinan, masyarakat sekitar hutan, tingkat kesejahteraan

\begin{abstract}
The Rinjani mountain region, especially the North Batukliang Setiling resort of Central Lombok district holds functions biological, ecological, and aesthetical and socio-economic functions for the community near the forest. Deforestation is often associated with the level of poverty of the community near the forest, so that introduction of the Community Forest $(\mathrm{HKm})$ in the region may increase people's income and reduce poverty. This research has been carried out using a descriptive-exploratory-participatory method by combining document
\end{abstract}


studies, structured interviews, in-depth interviews, and limited focus group discussions. The research was conducted at the villages of Aik Berik and Setiling with 40 respondents, as well as community leaders in the area. The collected data was analyzed descriptively by analysis of household income and per capita income which was then used to analyze the level of community welfare based on three different standards, namely Sajogyo, BPS, and the World Bank. The results of the study show that: 1) the average total household income of the community near the forest reaches Rp. 20,057,950 consisting of Rp. 13,597,950 (67.79\%) from the agricultural sector and Rp. 6,460,000 (32.21\%) from the non-agricultural sector with a per capita income of Rp. 4,667,549, - per year; 2) based on BPS criteria, the community around the forest in the North Batukliang sub-district is categorized as not poor, then based on the Sayogyo criteria produces an almost poor category, and the World Bank Criteria produce a poor category, so the three provide relatively different levels of welfare; 3 ) The presence of $\mathrm{Hkm}$ has been able to improve the welfare of the community near the forest because it is able to increase the per capita income of the community by 22.18 percent and has been able to alleviate poverty 7.5 to 22.5 percent. Therefore, it is suggested that the economic improvement of the community near the forest should be accelerated through policy interventions in business sectors which are on their main strengths, namely forestry, livestock, and plantations, as well as in non agricutural sector such as trade and other economic activities (such as home agroindustry).

Keywords: poverty, community near the forest, level of welfare

\section{PENDAHULUAN}

Kawasan pegunungan Rinjani memiliki fungsi sebagai kawasan yang harus dilindungi (protected areas) sehingga memiliki posisi yang strategis baik secara nasional maupun regional yang dapat memberikan benefit yang luar biasa bagi masyarakat (WWF, 2002; Yakin,2002; 2005). Kawasan Taman Nasional Gunung Rinjani (TNGR), khususnyaRresort Stiling merupakan kawasan penyuplai sumber daya air dan lingkungan utama bagi Kabupaten Lombok Tengah.Di kawasan ini juga terdapat potensi wisata yang sangat indah dan luar biasa untuk bisa dikembangkan seperti Benang Stokel, Benang Kelambu, Aik Bukak, Nyeredet (Air terjun dan mata air), Aik Bune, dan lain-lain (WWF, 2013).Sumberdaya hutan dan lingkungan seperti itu bisa merupakan sumber penghidupan bagi masyarakat miskin di dalam dan sekitar hutan (Wollenberg, dkk., 2004, Yakin dan Othman, 2003, Yakin, 2011, 2015).Namun demikian, pemanfaatan sumberdaya hutan yang berlebihan dan tidak terkendali dapat mengakibatkan kerusakan hutan dan mengurangi keberlanjutan fungsinya sebagai penyangga sistem kehidupan sehingga pemerintah mengeluarkan regulasi untuk mencegah hal tersebut selain memberikan akses yang lebih baik kepada masyarakat dengan mengelola lahan hutan (Dephut, 2009).

Kawasan dan sumberdaya hutan merupakan salah satu sumber penghasilan masyarakat di Kabupaten Lomboki Tengah, terutama di Kecamatan Batukliang Utara. Luas kawasan hutan secara keseluruhan di Kabupaten Lombok Tengah adalah 36.789,86 hektar yang terdiri dari 7830,10 hektar hutang lindung atau sekitar 21,28 persen, 9982,88 hektar hutan suaka alam dan pelestarian alam atau sekitar 27,13 persen, selanjutnya hutan produksi terbatas sebanyak 11489,10 hektar atau sekitar 31,23 persen, selanjutnya untuk hutan produksi permanen seluas 2149,29 hektar atau hanya sekitar 5,84 persen, serta hutan produksi yang bisa dikonversi seluas 5338,49 hektar atau sekitar 14,51 persen. Kalau dilihat dari komposisi hutan yang ada, maka dapat disimpulkan bahwa lebih dari setengahnya (51,58 \%) merupakan hutan produksi. 
Ini berarti bahwa sebagian besar dari fungsi di kawasan kecamatan Batukliang Utara ini adalah untuk keperluan ekonomi, ditambah lagi beberapa kawasan hutan lindung yang berfungsi sebagai obyek pariwisata termasuk untuk sumber air domestik, yang juga berkontribusi terhadap perekonomian masyarakat sekitar dan juga daerah. Kecamatan Batukliang Utara memiliki luas hutan yang paling besar, yaitu 8859, 05 hektar diikuti oleh kecamatan Praya Barat, Kecamatan Pujut, kecamatan Kopang, sedangkan kecamatan-kecamatan lainnya memiliki luas hutan kurang dari 1000 hektar (KLTDA, 2016). Selanjutnya, khususnya kecamatan Batukliang Utara terdiri dari 8(delapan) desa yang sebagian besar wilayahnya (73, $65 \%)$ adalah merupakan hutan negara, dan sisanya $(26,35 \%)$ merupakan daratan pemukiman dan lainnya. Hutan Negara yang luas tersebut tersebut tersebar merata di 4 desa, yaitu Desa Setiling dengan luas 3,201 hektar (85,09\%), desa Aik Berik dengan luas 3.483 hektar $(83,19$ $\%$ ), desa Lantan dengan luas 3.343 hektar (80,21 \%), dan desa Karang Sidemen dengan luas 3.342 hektar $(86,62 \%)$ (KBUDA, 2016). Pemanfaatan hasil hutan kayu adalah segala bentuk usaha yang memanfaatkan dan mengusahakan hasil hutan kayu dengan tidak merusak lingkungan dan tidak mengurangi fungsi pokok hutan. Kegiatan ini hanya dapat dilaksanakan pada areal hutan yang memiliki potensi untuk dilakukan kegiatan pemanfaatan hasil hutan kayu dan dapat dilaksanakan setelah diperoleh izin usaha, misalnya dalam bentuk Hutan Kemasyarakatan (HKm).

Terjadinya eforia era reformasi Indonesia pada tahun 1997-1999 juga berdampak pada fenomena perambahan hutan-hutan negara oleh masyarakat sekitar hutan sehingga mengalami degradasi hutan yang luar biasa, seperti juga yang terjadi di kecamatan Batukliang Utara. Banyak ahli (antara lain Fisher dan Hirsh, 2008 ) yang mengkaitkan deforestasi ini dengan kemiskinan masyarakat sekitar hutan.dan telah banyak kajian yang telah dilakukan tentang masyarakat miskin dan hutan baik di tingkat maupun global. Kasus Perambahan hutan tersebut selanjutnya diikuti dengan demonstrasi yang berkelanjutan agar hutan yang sudah dijarah tersebut diberikan hak pengelolaannya kepada masyarakat sekitar hutan. Akhirnya, pemerintah mengeluarkan kebijakan untuk memberikan hak pengelolaan Hutan Kemasyarakatan $(\mathrm{HKm})$ dengan tanpa hak milik melalui badan hukum yang sah yaitu Yayasan Darussadiqien pada tahun 2000 seluas 1800 hektar, yang dimulai oleh dengan menanam kembali tanaman kayu dan non kayu dengan konsep agroforestri yang saat ini pengelolaannya ditangani oleh Gabungan Kelompok Tani (GAPOKTAN) hutan. Pemberian hak HKm diprioritaskan pada masyarakat yang bertempat tinggal dan berbatasan langsung dengan kawasan hutan dan kehidupannya tergantung pada hasil hutan serta tidak memiliki lahan sawah atau yang memiliki lahan sempit, sehingga kebijakan ini selain untuk upaya pelestarian hutan tetapi juga dalam rangka meningkatkan kesejahteraan masyarakat sekitar hutan.

HKm tersebut terletak di bagian dalam dari Hutan Lindung yang sudah ditanam sejak tahun 1983, sehingga petani hutan yang menuju ke lahan HKm mereka haruss melalui hutan lindung ini. Pada tahun 2016, hutan lindung ini telah berumur 33 tahun dan HKm telah 16 tahun sehingga telah mulai menghasilkan kayu, serta hasil hutan bukan kayu (HHBK) seperti Durian, Kopi, Pisang, Sayuran, dan lain-lain. Kawasan Hkm ini dikembangkan Agroforestri dianggap sebagai salah satu strategi utama untuk pengelolaan hutan berkelanjutan serta pengurangan kemiskinan (Rahman et. al., 2010). Dengan demikian, keberadaan program HKm tersebut menambah alternatif sumber penghasilan masyarakat sekitar hutan baik dari produk kayu maupun produk hasil hutan bukan kayu sehingga yang menjadi pertanyaan adalah sejauh mana kehadiran program hutan kemasyarakatan ini berdampak terhadap tingkat kesejahteraan rumah tangga petani di kawasan tersebut. Dengan demikian keberhasilan pembangunan tidak hanya diukur dari pendapatan per kapita semata tetapi perlu juga dilihat dari distribusi pendapatan di antara para penduduknya (Aji, dkk., 2015). Analisis kemiskinan telah memperjelas pentingnya aset atau modal termasuk modal sosial dalam menentukan kesejahteraan (Scoones, 1998; Ashley and Canrey, 1999). Penggunaan dan pengelolaan sumberdaya dan ekosistem yang adalah hal yang mendasar bagi penghidupan masyarakat yang berkelanjutan. Dalam hal ini, dibutuhkan suatu keseimbangan antara peluang-peluang 
penghidupan untuk kesejahteraan ekonomi dengan tetap mempertahankan integritas ekologis dari ekosistem (IUCN, 2004).

Hasil kajian pada kasus Taman Nasional Ujung Kulon misalnya, salah satu penyebab kemiskinan struktural adalah sebagai konsekwensi logis dari model pengelolaan Taman Nasional yang didominasi pandangan dasar ekonomi-politik yang mengabaikan hak hidup manusia disekitar hutan, sehingga seluruh orientasi kegiatan pemberdayaan masyarakat justru menjauhkan masyarakat dari hal-hal yang menyangkut hutan dan kehutanan (Cahyono, 2012). Kenyataan juga menunjukkan bahwa kegiatan pengelolaan hutan yang lebih berorientasi pada pemanfaatan ekonomi telah memarginalkan masyarakat yang hidup di dalam dan sekitar hutan (Qodriyatun, 2013). Sumber daya yang dipanen, ditambang atau dimanfaatkan dari kawasan hutan bernilai sangat besar, akan tetapi masyarakat lokal hanya memperoleh sedikit keuntungan dari sumber daya yang bernilai begitu besar. Hampir tidak ada usaha di tingkat kebijakan sekalipun yang mengalokasi sebagian keuntungan tersebut untuk penanggulangan kemiskinan atau untuk investasi jangka panjang dalam aset manusia, keuangan, fisik ataupun aset alami. Dampak buruk terhadap lingkungan dan sosial akibat perkembangan lalu ditanggung oleh masyarakat setempat. Pembuat kebijakan cenderung memprioritaskan keuntungan ekonomi jangka pendek dengan mengorbankan hutan alam (Wollenberg, dkk., 2004).

Melihat kompleksitas hubungan antara pembangunan hutan berkelanjutan dengan kondisi sosial ekonomi rumahtangga atau masyarakat sekitar hutan di Kawasan Gunung Rinjani, khusus di Sektor Stiling Kecamatan Batukliang Utara maka yang menjadi permasalahan adalah sejauhmana kehadiran Hkm di kawasan hutan Batukliang Utara Kabupaten Lombok Tengah ini mampu meningkatkan kesejahteraan dan menekan kemiskinan masyarakat sekitarnya. Oleh karena itu penelitian ini telah menganalisis tingkat kesejahteraan rumahtangga sekitar hutan dan bagaimana dampaknya terhadap pengentasan kemiskinan masyarakat sekitar hutan dengan hadirnya program $\mathrm{HKm}$ di Kecamatan Batukliang Utara Kabupaten Lombok Tengah.

\section{METODE PENELITIAN}

\section{Rancangan Penelitian dan Teknik Pengumpulan Data}

Studi ini dilakukan dengan menggunakan metode deskriptif-eksploratif-partisipatif, dimana untuk mendapatkan data dan informasi objektif sesuai dengan kebutuhan studi, maka dilakukan pengumpulan data dan informasi dengan menggunakan berbagai pendekatan/teknik (Masri Singarimbun dan Sofyan Efendi, 1989; Burhan Bungin, 2008) yaitu: (1) Penelusuran dokumen terkait, (2) observasi langsung ke lapangan (direct observation); (3) wawancara semi struktur dan wawancara mendalam (in-depth interview), serta (4) Diskusi Kelompok Terarah (Focus Group Discussion).

\section{Penetapan Lokasi Penelitian dan Petani Responden}

Penelitian ini telah dilakukan di Kecamatan Batukliang Utara sebagai salah satu Kecamatan di Kabupaten Lombok Tengah yang berbatasan langsung dengan Kawasan hutan Gunung Rinjani sehingga masyarakatnya mempunyai interaksi langsung dengan kawasan hutan dalam membangun penghidupan mereka. Wilayah ini juga memiliki potensi yang bagus untuk pengembangan pariwisata (Benang Kelambu/Benang Stokel) serta potensi energi terbarukan berupa pembangkit tenaga listrik mikro Hidro (PLTMH), sehingga mempunyai potensi sebagai sumber penghidupan bagi masyarakat di wilayah tersebut. Penelitian dilakukan di Desa Aik Berik dan Desa Setiling yang ditentukan secara purposif sampling, dengan pertimbangan bahwa kedua desa tersebut berbatasan langsung dengan Kawasan Hutan Gunung Rinjani di Kabupaten Lombok Tengah, sekaligus dengan konsentrasi pemilik HKm yang 
besar..Jumlah responden ditentukan secara kuota sebanyak 40 orang yang terdistribusi masingmasing 20 orang pada tiap desa tersebut. Tokoh masyarakat dan informan kunci di wilayah tersebut dilibatkan dalam kelompok diskusi terarah (FGD).

\section{Variabel dan Cara Pengukurannya}

Kesejahteraan ekonomi masyarakat sekitar hutan ditunjukkan oleh tingkat pendapatan mereka, sehingga yang menjadi variabel utama dari penelitian ini adalah sumber pendapatan mereka baik dari kehutanan $(\mathrm{HKm})$ maupun non HKm. Dengan demikian, variable-variabel yang telah diukur dalam penelitian ini adalah sebagai berikut: (1)Karakteristik Responden dan Rumahtangga Masyarakat Sekitar hutan yang meliputi: umur pendidikan, jumlah tanggungan, pendidikan formal dan informal, dan sumber penghasilan, (2) Ragam sumber pendapatan rumahtangga petani sekitar hutan.

\section{Analisis Data}

Data dan informasi yang diperoleh dilakukan dengan analisis diskriprif, dengan menggunakan analisis pendapatan pada berbagai mata pencaharian atau kegiatan ekonomi rumahtangga atau masyarakat sekitar hutan serta analisis pendapatan per kapita yang selanjutnya digunakan untuk menganalisis tingkat kesejahteraan rumah tangga masyarakat sekitar hutan dengan mengkaitkannya dengan standar kesejahteraan dan/atau kemiskinan diberikan oleh Sajogyo (1982), Kriteria Bank Dunia, serta Kriteria pendekatan kebutuha dasar (basic needs approach) oleh Biro Pusat Statistik (BPS). Selanjutnya analisis dampak Hkm terhadap pengentasan kemiskinan diukur dengan membandingkan pendapatan per kapita masyarakat sekitar hutan dengan dimasukkan pendapatan dari Hkm dan tanpa pendapatan $\mathrm{Hkm}$ yang kemudian dianalisis pergeseran status tingkat kesejahteraan dan komposisi masyarakat miskin berdasarkan ketiga kriteria tersebut.

\section{HASIL DAN PEMBAHASAN}

\section{Karakteristik Responden}

Karakteristik responden mencerminkan profil masyarakat sekitar hutan yang menjadi sumber utama dari data yang dianalisis dalam studi ini. Responden masyarakat sekitar hutan memiliki karakteristik yang kompleks di mana kalau dilihat dari aspek umur, semua responden termasuk umur produktif (mengacu kepada BPS di mana 15 tahun ke atas adalah masuk kategori tenaga kerja produktif) dengan umur rata-rata masih relatif muda yaitu 46 tahun dengan kisaran antara 26 dan 65 tahun. Selanjutnya kalau dilihat dari usia berumahtangga, hasil penelitian menunjukkan jangka waktu yang bervariasi dengan kisaran 3-38 tahun dengan rata-rata usia berumahtangga 20 tahun. Kemudian dilihat dari jumlah tanggungan keluarga, hasil penelitian menunjukkan bahwa kisaran jumlah tanggungan keluarga bervariasi dari keluarga kecil sampai keluarga besar (1 - 11 orang) dengan rata-rata jumlah tanggungan keluarga sebanyak 4 orang, dan termasuk kategori sedang. Selanjutnya tingkat pendidikan yang diperoleh responden di mana sebagian besar ( 80 persen) memiliki pendidikan SLTP ke bawah, dan hanya sekitar 20 persen yang memiliki pendidikan SMA dan perguruan tinggi. Ini mengindikasikan bahwa upaya pemberdayaan masyarakat sekitar hutan harus terus dilakukan melalui upaya pengembangan kapasitas melalui pelatihan dan praktek sehingga bisa menyerap pengetahuan dan ketrampilan mereka yang disertai dengan pembinaan dan pendampingan yang berkelanjutan.

\section{Ragam Mata Pencaharian dan Tingkat Pendapatan Masyarakat Sekitar Hutan}

Mengukur tingkat kesejahteraan tidaklah mudah karena banyak indikator yang menentukan seseorang atau sebuah rumahtangga itu sejahtera atau tidak, misalnya terkait 
dengan faktor-faktor sosial, ekonomi, rohaniah, budaya, kenyamanan, keamanan, dan sebagainya, tetapi dalam kajian ini hanya terbatas dilihat dari aspek ekonomi, khususnya total pendapatan serta pendapatan per kapita. Aji, dkk. (2015) mengatakan bahwa walaupun pendekatan dengan menggunakan pendapatan ini terkesan ekonomi, namun pada kenyataanya pendapatan masih merupakan komponen paling penting dalam ekonomi rumah-tangga petani hutan. Selain itu, indikator yang digunakan untuk mengukur tingkat kesejahteraan masyarakat antara lain total pendapatan atau pendapatan per kapita. Pendapatan per kapita hanya merupakan gambaran secara umum dari kesejahteraan penduduk

Sumber dari total pendapatan rumahtangga masyarakat sekitar sangat beragam, dan komposisi pendapatan rumahtangga petani berdasarkan sumber perolehannya disajikan pada Tabel 1. Pada Tabel 1 tersebut dapat dilihat bahwa rata-rata total pendapatan rumahtangga masyarakat sekitar hutan mencapai Rp. 20.057.950 dengan pendapatan per kapita sebesar Rp. 4.667.549,-. Strategi penghidupan melalui diversifikasi usaha antara lain dengan hadirnya program HKm mampu meningkatkan pendapatan masyarakat sekitar hutan. Secara keseluruhan kalau dilihat dari komposisi pendapatan dari sektor pertanian dan sektor pertanian, data pada tabel 1 menunjukkan bahwa kontribusi pendapatan dari sektor pertanian dalam arti luas masih sangat dominan yaitu sebesar 67,79 persen terhadap total pendapatan per kapita rumahtangga atau masyarakat sekitar hutan dan hanya 32,21 persen yang bersumber dari sektor non pertanian. Kontribusi pendapatan dari sumber penghasilan baru seperti HKm, peternakan, serta perkebunan yang menjadi daya dukung utama dari masyarakat sekitar hutan ini kalau diakumulasi hampir mencapai 40 persen dari total pendapatan rumahtangga.Ini berarti pembinaan dan pengembangan ketiga sumber penghasilan ini ke depan mutlak diperlukan karena kekuatan utama masyarakat sekitar hutan adalah terkait dengan ketiga bidang usaha tersebut karena sesuai dengan kondisi sumberdaya alam dan lingkungan di sekitar mereka.

Selanjutnya bidang usaha lain yang menonjol adalah yang diharapkan ke depan adalah bidang usaha perdagangan dan kegiatan ekonomi produktif. Usaha perdagangan telah memberikan kontribusi yang cukup besar terhadap total pendapatan rumahtangga sementara dari usaha produktif masih sangat terbatas. Seiring dengan potensi pengembangan pariwisata di wilayah ini maka prospek kedua bidang usaha tersebut menjadi sangat terbuka dan berkembang, sehingga upaya peningkatan kesejahteraan masyarakat tidak hanya bertumpu pada pembinaan di sektor-sektor tradisionil seperti kehutanan, perkebunan, dan peternakan, tetapi juga pada sektor perdagangan serta kegiatan produktif, misalnya di bidang pengolahan hasil (agroindustri) hutan, kebun, dan ternak.

Tabel 1. Komposisi pendapatan rumahtangga petani berdasarkan Sumber Perolehannya di Kecamatan Batukliang Utara, 2016

\begin{tabular}{|c|l|r|c|}
\hline No & \multicolumn{1}{|c|}{ Sumber Pendapatan } & $\begin{array}{c}\text { Rata-rata Pendapatan } \\
\text { Per tahun (Rp) }\end{array}$ & $\begin{array}{c}\text { \% pendapatan } \\
\text { terhadap total } \\
\text { pendapatan }\end{array}$ \\
\hline \multicolumn{2}{|c|}{ Sektor Pertanian } & & \\
\hline 1 & Kehutanan (HKm dan lainnya) & 3.630 .525 & 18,10 \\
\hline 2 & Perkebunan/pekarangan & 2.568 .325 & 12,80 \\
\hline 3 & Sawah irigasi/tadah hujan & 275.000 & 1,37 \\
\hline 4 & Peternakan & 1.373 .500 & 8,62 \\
\hline 5 & Buruh tani dan buruh lainnya & 5.750 .600 & 28,67 \\
\hline & Sub-Total & $\mathbf{1 3 . 5 9 7 . 9 5 0}$ & $\mathbf{6 7 , 7 9}$ \\
\hline
\end{tabular}




\begin{tabular}{|c|l|r|c|}
\hline \multicolumn{2}{|l|}{ Sektor Non Pertanian } & & \\
\hline 6 & $\begin{array}{l}\text { Penghasilan tetap (pegawai negeri } \\
\text { swasta) }\end{array}$ & 3.765 .000 & 18,77 \\
\hline 7 & Perdagangan & 2.168 .000 & 10,81 \\
\hline 8 & Usaha/industri rumahtangga & 527.000 & 2,63 \\
\hline & Sub- Total & $\mathbf{6 . 4 6 0 . 0 0 0}$ & $\mathbf{3 2 , 2 1}$ \\
\hline $\begin{array}{l}\text { Rata-rata total Pendapatan rumah Tangga } \\
\text { Per tahun (termasuk Kehutanan) }\end{array}$ & 20.057 .950 & 100 \\
\hline
\end{tabular}

Sumber: Data primer diolah

\section{Analisis Tingkat Kesejahteraan Masyarakat Sekitar Hutan}

Dalam penelitian ini juga dikaji sejauhmana strategi penghidupan yang dilakukan oleh masyarakat sekitar hutan memberikan hasil (outcome) terhadap perbaikan kehidupan dan/atau kesejahteraan hidup mereka maka dinilai dengan melihat tingkat kesejahteraan masyarakat dengantingkat perdapatan per kapita per tahun mereka dengan mengacu pada tiga kriteria kesejahteraan atau kemiskinan yaitu Sayogyo, Bank Dunia, dan BPS. Hasil analisis tersebut disajikan pada Tabel 2 berikut.

Tabel 2. Estimasi Tingkat Pendapatan Per Kapita Per Tahun untuk Mengukur Tingkat Kesejahteraan Masyarakat Sekitar Hutan berdasarkan Kriteria Sayogyo, Bank Dunia, dan BPS tahun 2016

\begin{tabular}{|c|c|c|c|}
\hline No & Kriteria & $\begin{array}{c}\text { Kisaran Pendapatan (Rp. per kapita } \\
\text { per tahun) }\end{array}$ & Keterangan \\
\hline 1 & \multicolumn{2}{|c|}{ Bank Dunia (1 US \$ per hari) } & \multirow{3}{*}{$\begin{array}{l}1 \text { US } \$=\text { Rp. } 13.500 \text { per hari } \\
\text { atau Rp } 4.927 .500 \text { per kapita/ } \\
\text { tahun }\end{array}$} \\
\hline & Miskin & $<\operatorname{Rp} 4.927 .500$ & \\
\hline & Tidak miskin: & $\geq \operatorname{Rp} 4.927 .500$ & \\
\hline \multirow[t]{3}{*}{2} & \multicolumn{2}{|c|}{ Biro Pusat Statistik (BPS) } & \multirow{3}{*}{$\begin{array}{l}\text { Garis kemiskinan NTB untuk } \\
\text { semester } 1 \text { Maret } 2016 \text { untuk } \\
\text { pedesaan adalah Rp. } 326.656 \\
\text { per kapita/bulan atau Rp. } \\
\text { 3.919.872 /kapita/tahun }\end{array}$} \\
\hline & Miskin & $<\mathrm{Rp} 3.919 .872$ & \\
\hline & Tidak miskin: & $\geq \operatorname{Rp} 3.919 .872$ & \\
\hline \multirow[t]{5}{*}{3} & \multicolumn{2}{|l|}{ Sayogyo } & \multirow{5}{*}{$\begin{array}{l}\text { Asumsi Harga beras: Rp. } \\
10.000,- \text { per } \mathrm{kg}\end{array}$} \\
\hline & Miskin sekali & $\begin{array}{l}<240 \mathrm{~kg} \text { beras per kapita/tahun } \\
\text { atau Rp } 2.400 .000 / \mathrm{kapita} / \mathrm{tahun}\end{array}$ & \\
\hline & Miskin & $\begin{array}{l}240-320 \mathrm{~kg} \text { beras: } \mathrm{Rp} 2.400 .000- \\
\mathrm{Rp} 3.200 .000 / \text { kapita/tahun }\end{array}$ & \\
\hline & Hampir miskin & $\begin{array}{l}320-480 \mathrm{~kg} \text { beras: Rp } 3.200 .000- \\
\mathrm{Rp} 4.800 .000 / \mathrm{kapita} / \mathrm{tahun}\end{array}$ & \\
\hline & Tidak miskin & $\begin{array}{l}>480 \mathrm{~kg} \text { beras: }>\mathrm{Rp} 4.800 .000 / \\
\text { kapita/tahun. }\end{array}$ & \\
\hline
\end{tabular}

Sumber: Data primer diolah

Hasil estimasi ada Tabel 2 kemudian dikaitkan dengan tingkat pendapatan per kapita maka diketahui status tingkat kesejahteraan atau tingkat kemiskinan masyarakat sekitar hutan, seperti yang disajikan pada Tabel 3. Data tersebut menunjukkan bahwa setelah tingkat pendapatan per kapita masyarakat sekitar hutan di kecamatan Batukliang Utara dibandingkan dengan tingkat pendapatan menurut ketiga standar di atas ditemukan bahwa ketiga standar 
kesejahteraan memberikan hasil yang agak berbeda. Berdasarkan kriteria BPS, masyarakat sekitar hutan wilayah dimaksud masuk kategori tidak miskin. Walaupun secara umum kategorinya seperti itu setelah kaji lebih jauh tentang distribusi petani berdasarkan kategori ditemukan bahwa 50 persen responden masuk kategori miskin dan sisanya masuk kategori tidak miskin. Demikian juga dengan kategori dari Bank Dunia yang disimpulkan miskin, tetapi sesungguhnya ada diantara responden yang masuk kategori tidak miskin sebanyak 37,50 persen, sedangkan yang miskin sebanyak 62,50 persen.

Selanjutnya berdasarkan kriteria Sayogyo menghasilkan kategori yang tengah-tengah yaitu hampir miskin. Kriteria Sayogyo yang membagi empat kelompok bisa memberikan gambaran yang lebih kaya tentang distribusi kondisi tingkat kesejahteraan atau kemiskinan dimana yang masuk kategori tidak miskin hanya 40 persen, dan hampir miskin sebesar 27,50 persen, dan juga yang masuk kategori miskin sebesar 12,50 persen serta yang masuk kategori yang miskin sekali sebanyak 20 persen. Hal ini dimungkinkan karena ada gap yang lumayan tinggi antara yang pendapatan tertinggi dengan pendapatan terendah, yang dalam penelitian ini pendapatan per kapita tertinggi mencapai Rp. 10.500.000,- dan pendidikan per kapita terendah hanya mencapai Rp. 1.340.000.

Tabel 3. TingkatPendapatan Rumahtangga per Kapita Masyarakat Sekitar Hutan dikaitkan dengan Tingkat Kesejahteraan menurut Kriteria Sayogyo, Bank Dunia dan BPS di Kecamatan Batukliang Utara, 2016

\begin{tabular}{|c|c|c|c|c|}
\hline \multirow{2}{*}{ No } & \multirow{2}{*}{ Uraian } & \multicolumn{3}{|c|}{ Standar Kesejahteraan } \\
\hline & & Sayogyo & BPS & Bank Dunia \\
\hline & \multicolumn{4}{|c|}{ Perdapatan per kapita per tahun dengan Program HKm: Rp. 4.667.549,- } \\
\hline 1 & $\begin{array}{l}\text { Kategori umum } \\
\text { berdasarkan kriteria }\end{array}$ & $\begin{array}{c}\text { Hampir Miskin } \\
\text { (PP masuk } \\
\text { kategori ini) }\end{array}$ & $\begin{array}{c}\text { Tidak Miskin } \\
\text { (PP > Standar } \\
\text { BPS }\end{array}$ & $\begin{array}{c}\text { Miskin } \\
\text { PP }<\text { Standar } \\
\text { Bank Dunia }\end{array}$ \\
\hline \multirow[t]{7}{*}{2} & Komposisi (Jumlah dan \%) & & & \\
\hline & Miskin sekali & $8(20 \%)$ & & \\
\hline & Miskin & $5(12,50 \%)$ & $20(50 \%)$ & $25(62,50 \%)$ \\
\hline & Hampir miskin & $11(27,50 \%)$ & & \\
\hline & Tidak miskin & $16(40 \%)$ & $20(50 \%)$ & $15(37,50 \%)$ \\
\hline & \multicolumn{4}{|c|}{ Pendapatan per kapita per tahun ( tanpa Hkm): Rp. 3.820.331,- } \\
\hline & \multicolumn{4}{|c|}{ Kenaikan pendapatan per kapita dgn adanya Hkm: Rp. 847.209,- ( + 22,18\%) } \\
\hline 3 & $\begin{array}{l}\text { Kategori umum } \\
\text { berdasarkan kriteria }\end{array}$ & $\begin{array}{c}\text { Miskin } \\
\text { (PP masuk } \\
\text { kategori ini) }\end{array}$ & $\begin{array}{c}\text { Miskin } \\
\text { (PP > Standar } \\
\text { BPS }\end{array}$ & $\begin{array}{c}\text { Miskin } \\
\text { PP }<\text { Standar } \\
\text { Bank Dunia }\end{array}$ \\
\hline \multirow[t]{5}{*}{4} & Komposisi (Jumlah dan \%) & & & \\
\hline & Miskin sekali & $11(28 \%)$ & & \\
\hline & Miskin & $12(30 \%)$ & $24(60 \%)$ & $28(70 \%)$ \\
\hline & Hampir miskin & $4(10 \%)$ & & \\
\hline & Tidak miskin & $13(32,5 \%)$ & $16(40 \%)$ & $12(30 \%)$ \\
\hline \multirow[t]{5}{*}{5} & $\begin{array}{l}\text { Perubahan Kemiskinan } \\
\text { setelah ada HKm }(\%)\end{array}$ & & & \\
\hline & Miskin sekali & $-8 \%$ & & \\
\hline & Miskin & $-17,5 \%$ & $-10 \%$ & $-7,5 \%$ \\
\hline & Hampir miskin & $+17,5 \%$ & & \\
\hline & Tidak miskin & $+7,5 \%$ & $+10 \%$ & $+7,5 \%$ \\
\hline
\end{tabular}

Sumber: Data primer diolah

Dengan demikian, ketiga pendekatan dalam mengestimasi tingkat kesejahteraan dan/atau tingkat kemiskinan memberikan hasil yang berbeda. Oleh karena itu tingkat 
kemiskinan dari suatu wilayah tergantung dari standar yang digunakan, sehingga sehingga kalau standar kemiskinan dinaikkan maka jumlah orang miskin akan meningkat, sebaliknya kalau standar kemiskinan diturunkan maka jumlah orang yang miskin menjadi lebih kecil.

Selain mengukur tingkat kesejahteraan tersebut di atas, responden juga ditanyakan persepsi mereka tentang kondisi kehidupan mereka saat ini dibandingkan dengan ketika mereka baru memulai berumahtangga. Hasil penelitian menunjukkan bahwa persepsi responden terhadap perkembangan kondisi kehidupan mereka setelah berumahtangga menunjukkan keadaan yang meningkat yang ditunjukkan oleh sebanyak 33 responden $(82,50$ $\%)$ merasa lebih baik dibandingkan dengan saat awal mereka berumatangga, sedangakan sebanyak hanya 7 orang $(17,50 \%)$ yang menyatakan sama saja bahkan tidak ada yang merasa lebih jelek dari keadaan sebelumnya. Hasil ini sejalan penelitian Yakin (2002) menunjukkan bahwa kawasan Kawasan Gunung Rinjani Pulau Lombok memberikan dampak ekonomi yang memadai bagi masyarakat sekitar hutan.

\section{Dampak HKm terhadap Pengentasan Kemiskinan.}

Salah satu masalah serius di pedesaan khususnya masyarakat sekitar hutan adalah kemiskinan akibat dari terbatasnya sumberdaya yang dikuasai dan dimiliki. Keberadaan HKm memberikan peluang bekerja dan berusaha bagi masyarakat sekitar hutan serta berdampak pada berkembangnya usaha-usaha lain seperti pengolahan hasil hutan terutama yang bukan kayu (HHBK). Dampak HKm terhadap pengentasan kemiskinan ini dilihat dari sejauh mana berkurangnya rumahtangga miskin dengan hadirnya program $\mathrm{HKm}$ ini yaitu dengan membandingkan pendapatan rumahtangga an pendapatan per kapita tanpa HKm (pendapatan Hkm dikeluarkan) dan dengan adanya HKm, serta bagaimana pergeseran status kesejahteraan masyarakat berdasarkan ketiga kriteria yang digunakan serta perubahan komposisi tingkat kesejahteraan yang terjadi.

Hasil analisis pada Tabel 3 menunjukkan bahwa secara umum keberadaan program Hkm telah mampu meningkatkan pendapatan per kapita masyarakat sebesar 22,18 persen dan telah mampu mengentaskan kemiskinan pada masyarakat sekitar hutan di mana dengan adanya HKm kondisi umum kemiskinan masyarakat menurun berdasarkan tiga kriteria yang digunakan dalam penelitian ini menunjukkan bahwa masyarakat tanpa $\mathrm{Hkm}$ memiliki tingkat kesejahteraan miskin menjadi hampir miskin pada kriteria Sayogyo, berubah dari miskin menjadi tidak miskin untuk kriteria BPS dan kondisi umum sama yaitu miskin pada kategori Bank Dunia dengan tingkat pendapatan per kapita yang lebih baik. Dilihat dari komposisi pendapatan masyarakat berdasarkan kategori kesejahteraan yang dinilai, secara umum bahwa adanya program $\mathrm{HKm}$ telah menurunkan angka kemiskinan antara 7,5 sampai 22,5 persen. Dengan demikian, kehadiran Hkm bagi masyarakat miskin sekitar hutan bisa meningkatkan kesejahteraan mereka. Hasil penelitian ini memperkuat temuan Rahman et.al (2010) bahwa pengelolaan hutan yang berfokus pada masyarakat melalui agroforestri adalah strategi dan mekanisme yang layak untuk pengurangan kemiskinan.

\section{KESIMPULAN DAN SARAN}

\section{Kesimpulan}

1. Rata-rata total pendapatan rumahtangga masyarakat sekitar hutan mencapai Rp. 20.057.950 yang bersumber dari berbagai sumber pendapatan dengan pendapatan per kapita sebesar Rp. 4.667.549,-.Strategi diversifikasi mata pencaharian dengan hadirnya HKm mampu meningkatkan pendapatan masyarakat sekitar hutan. Kontribusi pendapatan dari sektor pertanian dalam arti luas masih sangat dominan yaitu sebesar 67,79 persen 
terhadap total pendapatan per kapita rumahtangga atau masyarakat sekitar hutan dan hanya 32,21 persen yang bersumber dari sektor non pertanian.

2. Setelah tingkat pendapatan per kapita masyarakat sekitar hutan di kecamatan Batukliang Utara dibandingkan dengan distribusi pendapatan berdasarkan kategori tingkat kesejahteraan dan/atau tingkat kemiskinan menurut kriteria Sayogyo, Bank Dunia, dan BPS ditemukan bahwa ketiga standar kesejahteraan memberikan hasil yang agak berbeda. Berdasarkan kriteria BPS, masyarakat sekitar hutan di kecamatan Batukliang Utara masuk kategori tidak miskin, tetapi kalau dirinci ditemukan bahwa 50 persen responden masuk kategori miskin dan sisanya (50 persen) masuk kategori tidak miskin. Berdasarkan kriteria Bank Dunia, rata-rata tingkat pendapatan per kapita masyarakat sekitar hutan tergolong miskin, tetapi sesungguhnya ada yang masuk kategori tidak miskin sebanyak 37,50 persen, sedangkan yang miskin sebanyak 62,50 persen. Selanjutnya berdasarkan kriteria Sayogyo menghasilkan kategori yang tengah-tengah yaitu hampir miskin. Kriteria Sayogyo yang membagi empat kelompok bisa memberikan gambaran yang lebih kaya tentang distribusi kondisi tingkat kesejahteraan atau kemiskinan dimana yang masuk kategori tidak miskin hanya 40 persen, dan hampir miskin sebesar 27,50 persen, dan juga yang masuk kategori miskin sebesar 12,50 persen serta yang masuk kategori yang miskin sekali sebanyak 20 persen. Hal ini dimungkinkan karena ada gap yang lumayan tinggi antara yang pendapatan tertinggi dengan pendapatan terendah, yang dalam penelitian ini pendapatan per kapita tertinggi mencapai Rp. 10.500.000,- dan pendidikan per kapita terendah hanya mencapai Rp. 1.340.000,-

3. Adanya Hkm telah mampu meningkatkan kesejahteraan masyarakat sekitar hutan karena keberadaannya program Hkm telah mampu meningkatkan pendapatan per kapita masyarakat sebesar 22,18 persen dan telah mampu mengentaskan kemiskinan pada masyarakat sekitar hutan di mana dengan adanya $\mathrm{HKm}$ kondisi umum kemiskinan masyarakat menurun berdasarkan tiga kriteria yang digunakan dalam penelitian ini menunjukkan bahwa masyarakat tanpa Hkm memiliki tingkat kesejahteraan miskin menjadi hampir miskin pada kriteria Sayogyo, berubah dari miskin menjadi tidak miskin untuk kriteria BPS dan kondisi umum sama yaitu miskin pada kategori Bank Dunia dengan tingkat pendapatan per kapita yang lebih baik. Dilihat dari komposisi pendapatan masyarakat berdasarkan kategori kesejahteraan yang dinilai, secara umum bahwa adanya program $\mathrm{HKm}$ telah menurunkan angka kemiskinan antara 7,5 sampai 22,5 persen.

\section{Saran}

1. Perbaikan ekonomi masyarakat sekitar hutan harus dipercepat melalui pola pembinaan dan pengembangan pada bidang-bidang usaha yang menjadi kekuatan utama mereka yaitu kehutanan, peternakan, dan perkebunan serta juga mendorong peningkatan kegiatan perdagangan dan ekonomi produktif skala rumahtangga.

2. Karena masyarakat berpandangan bahwa sangat penting untuk menjaga kelestarian fungsi-fungsi hutan, pemerintah dan pihak-pihak yang berkepentingan dalam upaya konservasi kawasan hutan setiap ada kegiatan yang menyangkut konservasi kawasan hutan harus melibatkan masyarakat sekitar hutan ini.

3. Keberadaan program-program dan bantuan baik dalam rangka pelestarian kawasan hutan termasuk pengembangan $\mathrm{HKm}$ maupun untuk pemberdayaan ekonomi masyarakat harus terus dilanjutkan agar kapasitas dan potensi masyarakat sekitar hutan bisa dikembangkan lebih jauh agar mampu meningkatkan kesejahteraan hidup mereka. 


\section{DAFTAR PUSTAKA}

Aji, Gutomo Bayu; Rusida Yuliyanti, Joko Suryanto, Andini Desita Ekaputra Tanjung Saptono, Hasriani Muis, 2015. Sumbangan Hutan Kemasyarakatan dan Hutan Desa terhadap Pendapatan dan Pengurangan Kemiskinan: Studi Kasus. Kerjasama penelitian antara: Pusat Penelitian Kependudukan LIPI dengan Kemitraan. The Partnership for Governance Reform. Jakarta.

Ashley, Caroline and Diana Carney, 1999). Sustainable livelihoods: Lessons from early experience. DFID: Department for International Development, London

Burhan Bungin, 2008. Metode Penelitian Kuantitatif: Komunikasi, Ekonomi, dan Kebijakan Publik serta Ilmu-Ilmu Sosial Lainnya. Cetakan ke 3. Prenada Media Group, Jakarta

Cahyono, Eko, 2012. Konflik Kawasan Konservasi dan Kemiskinan Struktural Jurnal Politika Vol. 8 No. 1 Tahun 2012 Politik Sumberdaya Alam

Departemen Kehutanan, 2009. PANGAN DARI HUTAN1 (Kontribusi Sektor Kehutanan Dalam Mendukung Ketahanan Pangan Nasional), Makalah pada Seminar Seminar Nasional dalam rangka "Hari Pangan Sedunia, 12 Oktober 2009", Jakarta, 1 Otober 2009. http://www.dephut.go.id/uploads/files/DEPHUT_Makalah_HPS.pdf

Fisher, Robert and Hirsch, Philip, 2008. Poverty and Agrarian-Forest Interactions in Thailand Geographical Research, March 2008. 46(1):74-84 doi: 10.1111/j.1745-5871.2007.00493.x

Masri Singarimbun, dan Sofyan Efendi, 1989. Metode Penelitian Survei. LP3ES, Jakarta.

Qodriyatun, Sri Nurhayati, 2013. Pengentasan Kemiskinan Masyarakat Sekitar Hutan Konservasi: Studi Pemberdayaan Masyarakat Melalui Model Desa Konservasi Diterbitkan oleh: P3DI Setjen DPR Republik Indonesia dan Azza Grafika 2013. http://berkas.dpr.go.id/pengkajian/files/buku_individu/buku-individu-7.pdf

Rahman, S.A.; K.M. Farhana, A. Imtiaj, S.W. Wachira, M.A. Rahman and S. Saha, 2010, Sustainable Forest Management for Poverty Reduction Through Agroforestry Options: Lesson from the Remote Uplands of Eastern Bangladesh. Libyan Agriculture Research Center Journal Internation 1 (3): 134-141, 2010.

UNEP, 2011. Climate Change, Conflict and Migration in the Sahel. Châtelaine, Geneva: The United Nations Environment Programme (UNEP)

Wollenberg, Eva; Brian Belcher, Douglas Sheil, Sonya Dewi, Moira Moeliono, 2004.

Mengapa kawasan hutan penting bagi penanggulangan kemiskinan di Indonesia?

Governance Brief: Forests and Governance Programme. Desember 2004 Nomor 4 (i).

Center for International Forestry Research.

http://www.cifor.org/publications/pdf_files/govbrief/GovBrief0404I.pdf

WWF, 2002. Penilaian Ekonomi Sumberdaya Kawasan Rinjani. Mataram, NTB

WWF, 2012. Laporan Studi Model dan Mekanisme Pengelolaan Jasa Lingkungan di Kabupaten Lombok Tengah. Mataram, NTB. 
Yakin, Addinul, 2002. The Impact of Development of Rinjani Mountain National Park toward the Farmer's Economy in the Surrounding Area: A case study at the Village of Senaru, District of West Lombok. Majalah Ilmiah Agroteksos, Vol. 12 (2), Oktober 2002.

Yakin, Addinul dan Jamal Othman, 2003. "Forest Resource and Policy at the Age of Regional Autonomy in Indonesia", Paper yang dipresentasikan pada the 2-day International Seminar on "Sustainable Economic, Business, and Social Development in an Era of Globalization", 13/10/2003-14/10/2003 at Equatorial Hotel, Bangi, Selangor, Malaysia.

Yakin, Addinul, 2005. Community Involvement and Environmental Management of Rinjani National Park, Lombok Island in Mitsuda and Sayuti (editors), Sustainable Lombok: The Rich Nature and Rich People in the 21st Century. Mataram: Universitas Mataram Press: 93-120.

Yakin, Addinul (2006). Implementation and Enforcement of Environmental Policies in Promoting Sustainable Development in Asia: Learning from Malaysia and Japan in Power, Purpose, Process, and Practice in Asia: The Work of API Fellows 2003/2004. Asian Public Intellectuals Program. Kuala Lumpur, Malaysia: Sasyaz Holdings Sdn. Bhd. Pages: 1-18.

Yakin, Addinul (2006). Kebijakan Pengelolaan Sumber daya Hutan dan Tata Pamong Lingkungan di Era Otonomi Daerah. Paper yang disampaikan pada Seminar Nasional tentang Kehutanan yang diselenggarakan di Hotel Jayakarta, Lombok: 9-11 Juni 2006.

Yakin, Addinul (2009). Analisis Sumberdaya Alam dan Pembangunan Ekonomi Berkelanjutan Propinsi NTB. Paper disampaikan pada Semiloka LECE -SUEZ oleh WWW Nusa Tenggara dan Pemda Tk. I NTB, Hotel Lombok Raya 21 Juli 2009.

Yakin, Addinul (2011),Prospek dan Tantangan Implementasi Pasar Karbon bagi Pengurangan Emisi Deforestasi dan Degradasi Hutan di Kawasan ASEAN. Paper disampaikan pada Seminar Nasional "Optimalisasi Integrasi Menuju Komunitas ASEAN 2015", Kerjasama Ditjen Kerja Sama ASEAN, Kemenlu RI dan Universitas Mataram di Grand Legi, Mataram, Sabtu 10 Desember 2011

Yakin, Addinul (2015), Ekonomi Sumber Daya Alam dan Lingkungan: Teori, Kebijakan, dan Aplikasi bagi Pembangunan Berkelanjutan. Edisi Baru Cetakan Ketiga. Akademika Pressindo Jakarta. 